\title{
Obando Martínez, Freddy \& González Campos, Guillermo. (2015) Historia del clan Kätsúibawák. Turrialba: Sede del Atlántico, Universidad de Costa Rica. 123 pp. Reseñado por Alice Lamounier Ferreira ${ }^{1}$
}

Recibido 30/VI/2015

"Historia del Clan Kätsúibawák" (UCR, Sede del Atlántico, 2015, 123 páginas) es un resultado más de la fructífera colaboración entre el lingüista Guillermo González y el cabécar Freddy Obando. Esa obra tiene como centro orbital la historia de origen de un clan del pueblo indígena cabécar de Costa Rica. Además de presentar una versión bilingüe (cabécar-español) de dicha historia direccionada, en principio, a los niños, el libro teje consideraciones sobre la cultura y lengua de los cabécares, que permiten a quien no los conoce, acercarse a ellos. Por otro lado, el volumen ofrece a los especialistas (maestros de lengua y cultura, antropólogos, lingüistas, etc.) una rica fuente de información y temas para incitar el debate. Así, cuanto a su público blanco, consideramos que el libro asume una tríplice vocación: niños, adultos no conocedores de la cultura cabécar y adultos especialistas.

La obra está dividida en tres grandes apartados: Presentación, Evocaciones para una mujer ave y su tribu de pericos. Estudio introductorio, y Kätsúibawák pákê. Los dos primeros son firmados por González y el último es una coautoría con Obando. En la Presentación, González sitúa al lector con relación a los antecedentes y motivaciones de la publicación. El segundo apartado puede ser definido como la parte técnica del libro, donde se analiza la historia a partir de cuestiones de carácter teórico-contextuales. Esa parte reúne cuatro sesiones: 1. La historia y su contexto, 2. Recursos formales de composición, 3. Antecedentes de la historia, 4. Sobre el texto aquí incluido. Mientras que el último apartado, Kätsúibawák páké, donde se encuentra la historia en sí misma, sería la sesión destinada al público infantil. Aunque su lectura no se limite a ese público, ya que el lenguaje utilizado permite la apreciación de los adultos. Asimismo, se resalta que ese apartado da origen al título de la obra en español y está subdividido en tres sesiones: 1. I jäkëwá irä i kuta irä (Los hermanos y la hermana), 2. Dínama (El Tigre de Río), 3. Kätsú (El Chucuyo).

Luego en las primeras páginas de la Presentación, González acota que ese pequeño libro fue concebido para ser un aporte a los textos educativos de las escuelas cabécares del Territorio

1 Alice Lamounier Ferreira, Maestría, Pontificia Universidad Católica de Minas Gerais, alicelamounier@gmail.com 
Indígena de Alto Chirripó. La precariedad en la cual trabajan los docentes que actúan en los territorios indígenas es bastante conocida sea del punto de vista de la formación que reciben sea con respecto a la infraestructura de las escuelas o a la carencia e inconsistencia de los materiales didácticos específicos para las clases de cultura y lengua (González Campos, 2011, Lamounier Ferreira, 2012, 2013). Ese último aspecto fue señalado por el autor:

...los maestros de lengua y cultura deben enseñar acuerpándose en pequeños folletos que de forma general se encuentran pésimamente escritos. La lengua cabécar sigue siendo hoy día un idioma restringido al ámbito oral y la población en general, incluidos los maestros, no saben cómo escribirlo de forma adecuada. Ello genera textos ortográficamente inconsistentes que, de ninguna manera, pueden servir de modelo escola. (González, 2015, 7).

Lograr la publicación de un "texto grandecito" (González, 2015, 6) en lengua vernácula y ortográficamente correcto ya sería, sin duda, una contribución extraordinaria a las escuelas cabécares, y cumpliría el fin inicialmente pensado por el autor. Sin embargo, se suman otras cualidades que hacen de la obra un marco esencial para la literatura indígena costarricense. En primer lugar se resalta el esmero estilístico de la versión en lengua nativa. Su narrador, Freddy Obando, es un profundo conocedor de su cultura, cantor de bulu siké (baile tradicional) y eximio contador de historia. Su versión de la historia del clan Kätsúibawá se singulariza por la profusión de detalles propia al estilo narrativo cabécar. Otras versiones de esa historia (inclusive bribris) ya habían sido publicadas, pero la brevedad y omisión de detalles que las definen, hacen con que se distancien de la forma tradicional de narrativa cabécar, y que se acerquen más a un resumen (ver Antecedentes de la Historia).

Otra cualidad relevante de la publicación es la serie de ilustraciones bonitas y coloridas que acompañan la historia. Tal hecho podría ser considerado banal en un contexto citadino y de lengua dominante (en el caso el español), donde los libros infantiles nacionales o importados, proliferan en las librerías. Sin embargo, para el Territorio Indígena de Alto Chirripó, eso puede ser considerado como raro, ya que en ese ámbito circulan pocos libros y casi ninguno en lengua vernácula. Al propiciar a los niños cabécares una obra bien redactada en su idioma materno y con ilustraciones a colores, se les permite un acceso privilegiado a una historia tradicional. Las palabras impresas resuenan, como pocas veces, a lo que les cuentan sus mayores. Las historias oídas en sus casas se hacen presentes en el ambiente escolar. A su vez, las ilustraciones también dialogan con sus experiencias sensoriales cotidianas: la montaña, la casa tradicional, los senderos, el río, los seres (humanos y no humanos) presentados... todo contribuye a una identificación entre el representado 
en los dibujos y el universo socio-cosmológico conocido por niños indígenas. Así, el conjunto de textos y dibujos aporta para que esos niños se reconozcan en la historia y afirmen su identidad. Como se ha observado anteriormente, la contribución de la "Historia del Clan Kätsúibawák" también puede ser percibida desde el punto de vista de un público adulto especializado o no. González ha tenido el cuidado de exponer problemáticas de orden general sobre de la cultura cabécar. Así, se proporciona a los principiantes un panorama de algunos ejes centrales como el parentesco y la lengua. En ese sentido, el texto tiene el valor de presentar una pequeña sistematización de cuestiones sobre los clanes matrilineales cabécares.

Sin embargo, su mayor contribución está en el campo de la antropología lingüística o sociolingüística, pues profundiza el análisis de las características formales del texto en cuestión, al mismo tiempo que busca el establecimiento de relaciones entre estas y la literatura indígena regional. En el Estudio Introductorio, González apunta diversas características propias a la historia de Kätsúibawák, como el paralelismo, las líneas temáticas básicas, los fenómenos fónicos, el tipo de estructura narrativa o el suspense.

Los autores son extremamente cuidadosos en la realización de la traducción libre y proponen que la versión en español guarde ciertas características centrales del género de narración oral cabécar, como por ejemplo el paralelismo. Aunque, al tomar ese sendero se obtuviera como consecuencia una traducción de estilo inusitado o de estética poco ortodoxa en español. González asume el riesgo conscientemente:

Al nivel estilístico, se ha intentado reproducir los recursos literarios utilizados por él narrador [Freddy Obando], a pesar de que a veces se generan repeticiones que, en español no suenan bien. La idea es que quien no domina la lengua cabécar, pueda leer el texto y hacerse una idea general de cómo es el original. (González, 2015, 58).

La intención es clara: al lugar de hacer una versión más próxima a los géneros narrativos comúnmente desarrollados en español, se ha decidido dar a conocer el estilo de la literatura oral cabécar. Al privilegiar la representación estilística de la lengua vernácula en la traducción, se pone en evidencia las divergencias de sus características formales y estéticas con la(s) tradición(es) literaria(s) escrita(s) en lengua española.

Kätsúibawák pákế ofrece al lector una trama que vincula dos temáticas básicas: el relato de origen de un clan y el matrimonio entre humanos y animales. Ambas temáticas fueran bien identificadas y analizadas por González tanto con respecto a su presencia en la tradición narrativa cabécar 
denominada páké (narrar, contar), como en relación a su consonancia regional (y mismo continental) con otras artes verbales amerindias.

Sobre la estructura narrativa, González logra identificar elementos originales al fundamentar la división del texto en tres partes distintas bajo el ángulo del narrador. Según el autor, la primera sesión, I jäkếwá irä i kuta irä (Los hermanos y la hermana), tiene un narrador heterodiegético; la segunda, Dínama (El Tigre de Río), autodiegético; mientras la tercera, 3. Kätsú (El Chucuyo) regresa al tipo heterodiegético. Como recurso estilístico, el cambio de narrador es empleado para dinamizar la narrativa y atraer la atención de los oyentes (se recuerda que se trata de un arte oral). Ese constato nos lleva a nuevas interrogantes: ¿Ese cambio dinámico de narrador seria una estrategia propia de las estructuras de las historias cabécares (pákế)? Es decir, ¿se podría encontrar en ese aspecto un patrón de las narrativas cabécares? O ¿Seria solamente un caso aislado? ¿Tal hecho estaría relacionado al estilo personal de contar historias de Obando? Así, al propiciar una publicación de cualidad de una historia cabécar, se posibilita la identificación sistemática de elementos propios a la narrativa tradicional, y se permite un doble movimiento de análisis: el acercamiento a otras artes verbales amerindias y el distanciamiento de la tradición europea. Al poner en evidencia las características del arte verbal cabécar, se contribuye para suplantar la idea que esa no es bella o que le hace falta estilo. De un modo opuesto, el libro de González y Obando nos muestra cuáles son las características y cualidades estética propias al estilo cabécar. Tal hecho permite la construcción de argumentos claros para la superación de prejuicios de carácter sociolingüísticos que pesan sobre el pueblo cabécar.

Todo lo anterior permite considerar que el valor del libro sobrepasa los límites del Territorio Indígena de Alto Chirripó y del dominio escolar. La publicación puede ser considerada como contribución para las escuelas del resto del país con respecto a dar a conocer a una tradición indígena actual de Costa Rica. Por ser una edición bilingüe, permite al público infantil y adulto conocer la diversidad sociocultural del país, tan frecuentemente ignorada y minimizada por las autoridades gubernamentales y por el censo común.

Sin lugar a duda, la publicación de ese libro pone a relucir nuevos conocimientos sobre los cabécares y, en especial, coloca en pauta la posibilidad de suscitar más y necesarios debates sobre el tema indígena. Es un texto rico por provocar a sus lectores interrogantes novedosas sobre las narrativas cabécares. Por todo lo acotado, se considera que obra en cuestión es accesible y expone de forma clara elementos sociolingüísticos fundamentales del arte verbal cabécar, por lo que creemos ser de lectura indispensable a todos que se interesan por la cuestión indígena. 


\section{Bibliografía}

González Campos, Guillermo. (2011). Dificultades para normalización ortográfica y problemas de escritura entre los cabécares de Chirripó. Estudios de Lingüística Chibcha, 30, 7-35.

Lamounier Ferreira, Alice. (2012). Algunas reflexiones sobre la enseñanza del cabécar como lengua materna en las escuelas primarias. Revista Voces, 7 (1), Enero-junio, 87-101. Guatemala.

Lamounier Ferreira, Alice. (2013). ¿En cabécar o español? Bilingüismo y diglosia en Alto Chirripó. Cuadernos Inter.c.a.mbio, 10, (10),12, 105-119. 